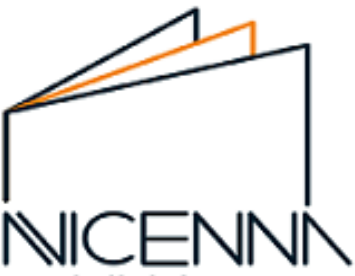

publishing $\mathrm{co}$.

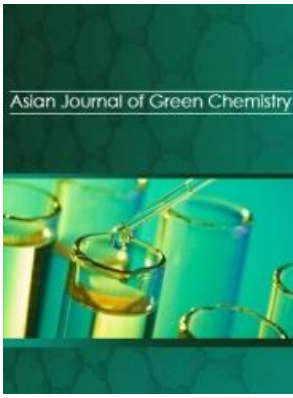

Original Research article

\title{
Silica-supported $\mathrm{HClO}_{4}$ and $\mathrm{KHSO}_{4}$ as reusable green catalysts for sulfonation of aromatic compounds under solvent-free conditions
}

Touheeth Fatima, Yeike Hemanth Sriram, Mukka Satish Kumar, Marri Venkateswarlu,

Kamatala Chinna Rajanna*

Department of Chemistry, Osmania University, Hyderabad (T.S)-500007 India

\section{ARTICLE INFORMATION}

Received: 16 August 2017

Received in revised: 23 August 2017

Accepted: 30 August 2017

Available online: 31 August 2017

DOI: 10.22631/ajgc.2017.95574.1016

\section{KEYWORDS}

Si-supported BrØnsted acids

Green reuasble catalysts

$\mathrm{NaHSO}_{3}$

Sulfonation

Aromatic compounds

\section{ABSTRACT}

A green protocol is described for sulfonation of aromatic compounds that has been accomplished using sodium bisulfite $\left(\mathrm{NaHSO}_{3}\right)$ in the presence of reusable green heterogeneous $\mathrm{SiO}_{2} / \mathrm{HClO}_{4}$ and $\mathrm{SiO}_{2} / \mathrm{KHSO}_{4}$ (Silicasupported $\mathrm{HClO}_{4}$ and $\mathrm{KHSO}_{4}$ catalysts) under conventional and solvent-free microwave irradiation. The reactions afforded very good yields of products within 3 to 5 hour under conventional conditions. However, the reaction times in microwave-assisted protocol are drastically reduced to 3 to 5 minutes (from 3 to 5 hour under conventional conditions) followed by increasing product yields. Moreover, the developed silica-supported catalysts could be recycled for at least three to four times. 


\section{Graphical Abstract}

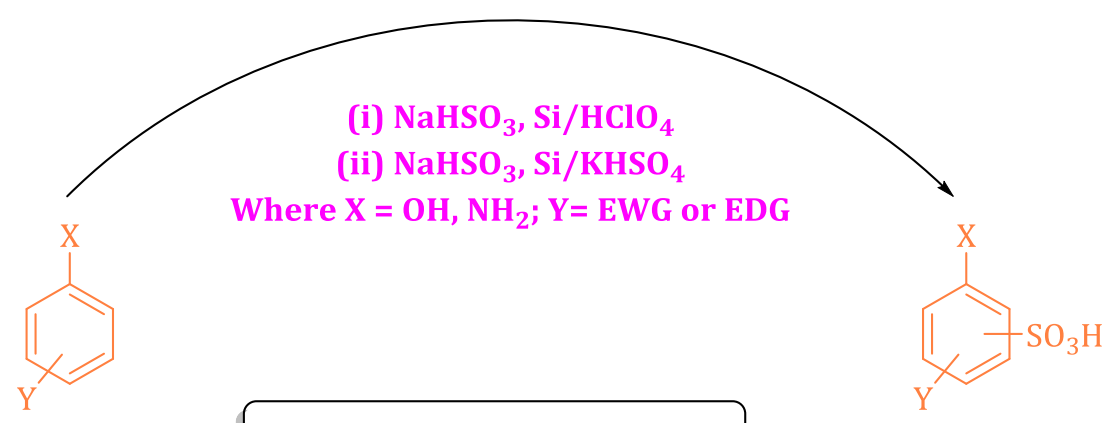

(i) Acetonitrile, reflux (ii) Solvent-free, microwave

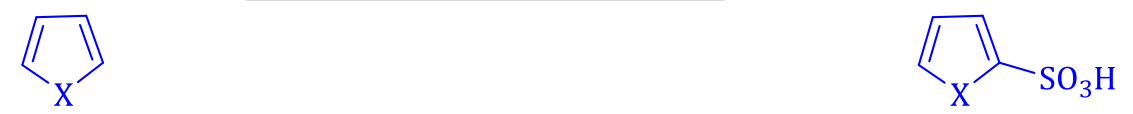

\section{Introduction}

For over 150 years, electrophilic aromatic substitution reactions such as sulfonation of aromatic compounds [1-12] received the attention of synthetic chemists because many of the sulfonated aromatic are useful reactive intermediates to prepare pesticides, pharmaceuticals, polymers and several industrial products. Sulfonation is the introduction of sulfonic acid group $\left(-\mathrm{SO}_{3} \mathrm{H}\right)$ or $\mathrm{SO}_{3}$ electrophile into an aromatic entity. Sulfonation of aromatic hydrocarbons is generally achieved by using sulfuric acid, sulfur trioxide, or chloro sulfuric acid [12]. Besides these, sulfonation could also be achieved by the reaction of organic halogen compounds with inorganic sulfites; and the oxidation of thiols, disulfides, and certain classes of organic sulfur compounds [13]. A perusal of literature shows that Brønsted acids and bases could also be used as catalysts in a number of electrophilic aromatic substitution reactions, but some of these catalysts are toxic, volatile, expensive, hazardous, and difficult to handle. Laboratory drains of such hazardous acids and bases cause environmental pollution.

In recent past, several aluminium and silica-supported acid catalysts are developed to overcome these issues, which afforded better yields and productivity in comparison to conventional protocols [14-24], because solid supported catalysts possess high surface, long catalytic life, environment-friendliness, and provide good to excellent yields with simple work-up procedure. 
We have recently explored silica supported $\mathrm{HClO}_{4}$ and $\mathrm{KHSO}_{4}$ materials as reusable green catalysts for thiocyanation of aromatic compounds under conventional and solvent-free microwave assisted conditions [24]. Stimulated by the noteworthy advantages of silica-supported catalysts, we have embarked on exploring silica supported $\mathrm{HClO}_{4}$ and $\mathrm{KHSO}_{4}$ as an efficient catalysts for sulfonation of aromatic compounds in the present study (Schem 1).

\section{Experimental}

\section{Matreials and methods}

Chemicals used in this study are reagent grade, which are purchased from Aldrich, SD-fine chemicals Avra, and used as such. Thin layer chromatography (TLC) experiments were carried out using Merck aluminum-backed $0.2 \mathrm{~mm}$ silica gel 60 F-254 plates. Merck silica gel 60 (230-400 mesh) was used to perform Column chromatography. Microwave-assisted (MWA) reactions were performed in a bench mate model microwave oven (CEM-908010, bench mate model, 300W laboratory microwave reactor) was used in this study. Method of the preparation, and characterization of Silica supported catalysts $\left(\mathrm{SiO}_{2} / \mathrm{KHSO}_{4}\right.$ and $\left.\mathrm{SiO}_{2} / \mathrm{HClO}_{4}\right)$ is the same as reported in our recent publication [24].

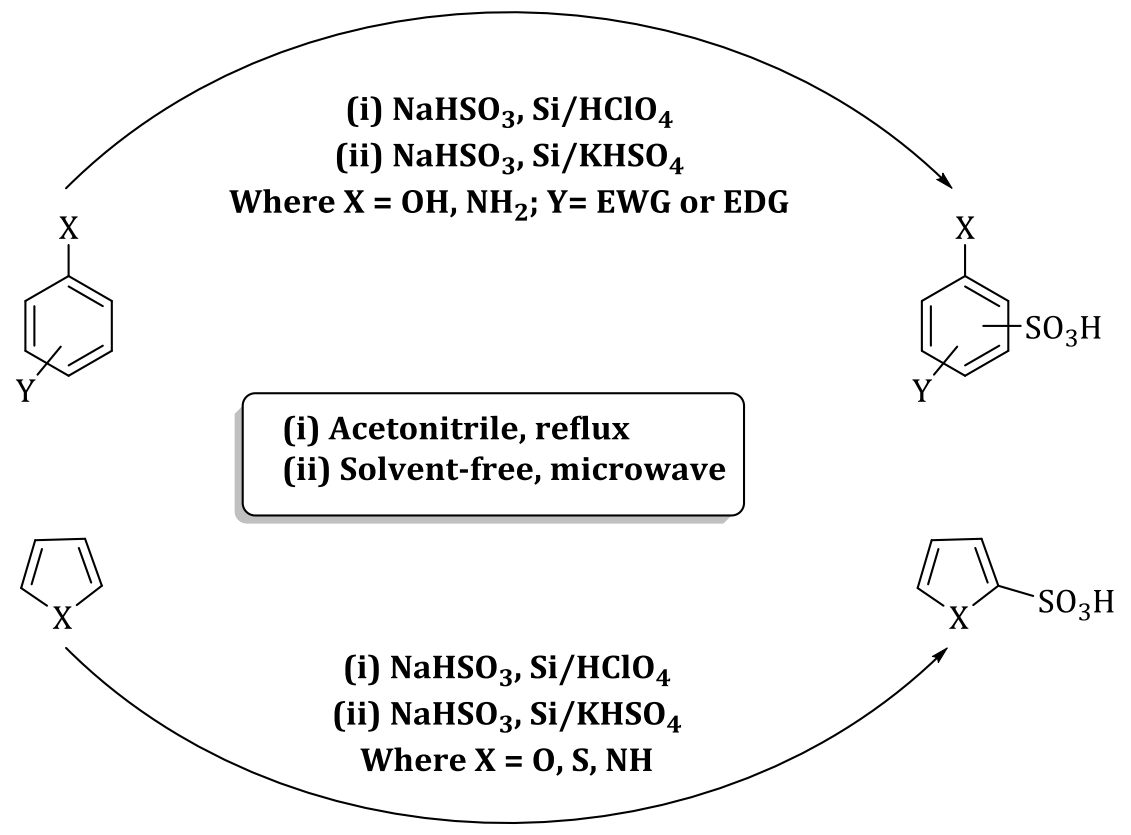

Scheme 1. Sulfonation of aromatic compounds using $\mathrm{SiO}_{2} / \mathrm{HClO}_{4}$ and $\mathrm{SiO}_{2} / \mathrm{KHSO}_{4}$ catalysts Sulfonation of aromatics using $\mathrm{SiO}_{2} / \mathrm{KHSO}_{4}$ under conventional reflux conditions

The catalyst $\left(0.30 \mathrm{~g}\right.$ of $\mathrm{SiO}_{2} / \mathrm{KHSO}_{4}$ or $\left.\mathrm{SiO}_{2} / \mathrm{HClO}_{4}\right)$ was added to the mixture of aromatic compound (10 mmol), $\mathrm{NaHSO}_{3}$ and acetonitrile, were taken in a previously cleaned round bottom 
flask and stirred under reflux conditions. The progress of the reaction was monitored by TLC. After the completion of the reaction, the catalyst was separated and the reaction mixture is was treated with $\mathrm{NaHCO}_{3}$ solution, followed by the addition of ethyl acetate. The organic layer was separated, dried over $\mathrm{Na}_{2} \mathrm{SO}_{4}$ and evaporated under vacuum, purified with column chromatography to get pure product. The products of the reactions are characterized by spectroscopic methods.

Microwave-assisted sulfonation of aromatics under solvent-free conditions

For aromatic sulfonation, the contents such as aromatic compound (10 mmol), $\mathrm{NaHSO}_{3}$ and optimum quantity $(0.30 \mathrm{~g})$ of the catalyst $\left(\mathrm{SiO}_{2} / \mathrm{KHSO}_{4}\right.$ or $\left.\mathrm{SiO}_{2} / \mathrm{HClO}_{4}\right)$ were taken in a previously cleaned beaker, mixed thoroughly and placed in micro-wave oven. The progress of the reaction was monitored by TLC. After the completion of reaction, the reaction mixture was filtered and is treated with $\mathrm{NaHCO}_{3}$ solution and followed the same procedure as mentioned above.

\section{Results and discussion}

In order to optimize the reaction conditions, sulfonation was carried out with varied concentrations of silica-supported catalyst, and the results are presented in Table 1 . The data compiled in Table 1 revealed that optimum quantity of $\mathrm{SiO}_{2} / \mathrm{HClO}_{4}$ catalyst for nitration reaction is $0.2 \mathrm{~g}$ whereas $\mathrm{SiO}_{2} / \mathrm{KHSO}_{4}$ catalyst is $0.25 \mathrm{~g}$. Further increase of catalyst amount did not appreciably affect the yield of the product. The conversion yields of the nitration of phenol presented in Table 1 also indicate that the best results are obtained with $\mathrm{SiO}_{2} / \mathrm{HClO}_{4}$ over $\mathrm{SiO}_{2} / \mathrm{KHSO}_{4}$ catalyst. This is because $\mathrm{HClO}_{4}$ is a stronger acid than $\mathrm{KHSO}_{4}$ (Perchloric acid is a superacid with pKa $=-10.0$ to 15.0, while pKa of $\mathrm{HSO}_{4}^{-}=1.8$ ); and it is also a stronger acid than either sulfuric (pKa $=-10.0$ from sulfuric to bisulfuric) or nitric acid ( $\mathrm{pKa}=-2.0$ ). Thus, $\mathrm{HClO}_{4}$ provides strong acidity with minimal interference because perchlorate is weakly nucleophile, whereas $\mathrm{KHSO}_{4}$ creates an acidic environment due to the complete protolysis of the ion $\mathrm{HSO}_{4}^{-}$. Acidity (pKa) of both $\mathrm{HSO}_{4^{-}}$and $\mathrm{HSO}_{3}{ }^{-}$ is almost equal to one another $(\mathrm{pKa}=1.8)$. Bisulfite $\left(\mathrm{HSO}_{3}^{-}\right)$is the conjugate base of sulfurous acid, $\mathrm{H}_{2} \mathrm{SO}_{3}$ :

$$
\mathrm{H}_{2} \mathrm{SO}_{3} \rightleftharpoons \mathrm{HSO}_{3}^{-}+\mathrm{H}^{+}
$$

${ }^{17} \mathrm{O}$ NMR spectroscopy provided evidence that solutions of sulfurous acid and protonated sulfites contains a mixture of isomers, which is in equilibrium:

$$
\left[\mathrm{H}-\mathrm{OSO}_{2}\right]^{-} \rightleftharpoons\left[\mathrm{H}-\mathrm{SO}_{3}\right]^{-}
$$


Table 1. Effect of Catalyst and on the sulfonation of aromatic compounds

\begin{tabular}{ccccc} 
Entry & \multicolumn{2}{c}{$\mathrm{SiO}_{2} / \mathrm{HClO}_{4}$} & \multicolumn{2}{c}{$\mathrm{SiO}_{2} / \mathrm{KHSO}_{4}$} \\
& Amount of catalyst (g) & Yield (\%) & Amount of catalyst (g) & Yield (\%) \\
1 & 0.1 & 50 & 0.1 & 45 \\
2 & 0.15 & 70 & 0.15 & 62 \\
3 & 0.20 & 87 & 0.20 & 68 \\
4 & 0.25 & 94 & 0.25 & 75 \\
5 & 0.3 & 95 & 0.3 & 80 \\
6 & - & - & 0.4 & 81 \\
\hline
\end{tabular}

Data presented in Table 2 show that benzene did not undergo sulfonation, but other substituted benzenes underwent sulfonation smoothly in 2 to 4 hours, under conventional heating followed by constant stirring), and afforded corresponding sulfonic acids as ascertained by spectroscopic studies. Sulfonation of toluene (Table 1, entry 1) gave 4-methyl benzene sulfonic acid as major part, (o:m:p ratio: 10:0:90) with isolated 90\% yield. However, all the other aromatic hydrocarbons (Table 2, entries: 2-11) afforded only para derivatives. In an attempt to avoid refluxing the reaction mixtures at elevated temperatures, we have carried out the experiments under microwave irradiation, using an a microwave oven.

Reaction times in microwave-assisted reactions are at least four to eight times less than conventional thermal method followed by substantial increase of product yields. It is interesting to note that the sulfonation of toluene under sonication not only reduced the reaction time but also the para derivative (4-methyl benzene sulfonic acid; Table 2, entry 1 ) is further increased (o:m:p) ratio from (10:0:90) to (5:0:95) with isolated yield from $90 \%$ to $95 \%$. In all the other cases (Table 2, entries 2-11), the product yield is largely increased from to 2 to $5 \%$. Inspired by the green chemistry principles $[25,26]$, we have conducted the reactions under microwave irradiation.

Observed dramatic rate accelerations in microwave assisted reactions could be attributed to bulk activation of molecules due to direct thermal and uniform heating during course of microwave irradiation [27-31], as explained in earlier literature reports (Table 3).

Mechanism of silica-supported $\mathrm{KHSO}_{4}$ and $\mathrm{HClO}_{4}$ induced sulfonation could be explained by considering their interaction with $\mathrm{NaHSO}_{3}$ in the first step to give sulfurous acid $\left(\mathrm{H}_{2} \mathrm{SO}_{3}\right)$. In the second step, $\pi$-electron enriched aromatic hydrocarbon captures bisulphite $\left(\mathrm{HSO}_{3}\right)^{+}$electrophile from sulfurus acid to afford aryl sulfonic acids, favored by soft-soft interactions between electrophile (a soft acid) and aromatic hydrocarbon (a soft base) as shown in Scheme 2. 
Table 2. Sulfonation of aromatic compounds in presence of $\mathrm{SiO}_{2} / \mathrm{HClO}_{4}$ catalyst

\begin{tabular}{|c|c|c|c|c|c|c|}
\hline \multirow[b]{2}{*}{ Entry } & \multirow[b]{2}{*}{ Substrate } & \multirow[b]{2}{*}{ Product } & \multicolumn{2}{|c|}{ Conventional } & \multicolumn{2}{|c|}{ Microwave } \\
\hline & & & $\begin{array}{l}\text { R. T } \\
\text { (h) }\end{array}$ & $\begin{array}{c}\text { Yield } \\
(\%)\end{array}$ & $\begin{array}{l}\text { R. T } \\
\text { (min) }\end{array}$ & $\begin{array}{c}\text { Yield } \\
(\%)\end{array}$ \\
\hline 1 & Phenol & 4-hydroxybenzene sulfonic acid & 3 & 79 & 2 & 74 \\
\hline 2 & Aniline & 4-aminobenzene sulfonic acid & 2.5 & 81 & 3 & 87 \\
\hline 3 & Anisole & 4- methoxybenzene sulfonic acid & 2 & 74 & 1 & 79 \\
\hline 4 & Quinol & 2,5 dihydroxybenzene sulfonic acid & 1.5 & 68 & 2 & 72 \\
\hline 5 & $p$-nitro phenol & 5-hydroxy 2-nitrobenzene sulfonic acid & 2 & 80 & 4 & 93 \\
\hline 6 & $p$-amino phenol & 2-amino 5-hydroxybenzene sulfonic acid & 3 & 76 & 3 & 81 \\
\hline 7 & $p$-cresol & 5-hydroxy 2-methylbenzene sulfonic acid & 2.5 & 71 & 2 & 71 \\
\hline 8 & Catechol & 3,4-dihydroxybenzene sulfonic acid & 2 & 78 & 2 & 93 \\
\hline 9 & m-Chloro phenol & 2-chloro 4-hydroxybenzene sulfonic acid & 3 & 66 & 3 & 76 \\
\hline 10 & Chloro benzene & 2-chloro 4-hydroxybenzene sulfonic acid & 3.5 & 65 & 4 & 73 \\
\hline 11 & Toluene & 4-methyl benzene sulfonic acid & 3 & 68 & 3 & 75 \\
\hline 12 & Indole & 1H-indole-4-sulfonic acid & 4 & 76 & 2 & 84 \\
\hline 13 & Pyrrole & 1H-pyrrole-4-sulfonic acid & 3.5 & 71 & 2 & 86 \\
\hline 14 & Furan & Furan-2-sulfonic acid & 2.5 & 79 & 3 & 87 \\
\hline
\end{tabular}

Table 3. Sulfonation of aromatic compounds in presence of $\mathrm{SiO}_{2} / \mathrm{KHSO}_{4}$ catalyst

\begin{tabular}{|c|c|c|c|c|c|c|}
\hline \multirow[b]{2}{*}{ Entry } & \multirow[b]{2}{*}{ Substrate } & \multirow[b]{2}{*}{ Product } & \multicolumn{2}{|c|}{ Conventional } & \multicolumn{2}{|c|}{ Microwave } \\
\hline & & & $\begin{array}{l}\text { R. T } \\
\text { (h) }\end{array}$ & $\begin{array}{c}\text { Yield } \\
(\%)\end{array}$ & $\begin{array}{c}\text { R. T } \\
\text { (min) }\end{array}$ & $\begin{array}{c}\text { Yield } \\
(\%)\end{array}$ \\
\hline 1 & Phenol & 4-hydroxybenzene sulfonic acid & 4 & 69 & 3 & 71 \\
\hline 2 & Aniline & 4-aminobenzene sulfonic acid & 5 & 73 & 5 & 77 \\
\hline 3 & Anisole & 4- methoxybenzene sulfonic acid & 3.5 & 61 & 4 & 76 \\
\hline 4 & Quinol & 2,5 dihydroxybenzene sulfonic acid & 4 & 59 & 4 & 62 \\
\hline 5 & $p$-nitro phenol & 5-hydroxy 2-nitrobenzene sulfonic acid & 3.5 & 78 & 1 & 59 \\
\hline 6 & $p$-amino phenol & 2-amino 5-hydroxybenzene sulfonic acid & 4.5 & 77 & 4 & 84 \\
\hline 7 & $p$-cresol & 5-hydroxy 2-methylbenzene sulfonic acid & 2.5 & 55 & 3 & 68 \\
\hline 8 & Catechol & 3,4-dihydroxybenzene sulfonic acid & 3.5 & 88 & 5 & 83 \\
\hline 9 & m-Chloro phenol & 2-chloro 4-hydroxybenzene sulfonic acid & 4 & 56 & 4 & 61 \\
\hline 10 & Chloro benzene & 2-chloro 4-hydroxybenzene sulfonic acid & 3.5 & 70 & 4 & 78 \\
\hline 11 & Toluene & 4-methyl benzene sulfonic acid & 3 & 68 & 3 & 75 \\
\hline 12 & Indole & 1H-indole-4-sulfonic acid & 2.5 & 69 & 5 & 73 \\
\hline 13 & Pyrrole & 1H-pyrrole-4-sulfonic acid & 3.5 & 68 & 4 & 71 \\
\hline 14 & Furan & Furan-2-sulfonic acid & 5.0 & 73 & 2 & 69 \\
\hline
\end{tabular}




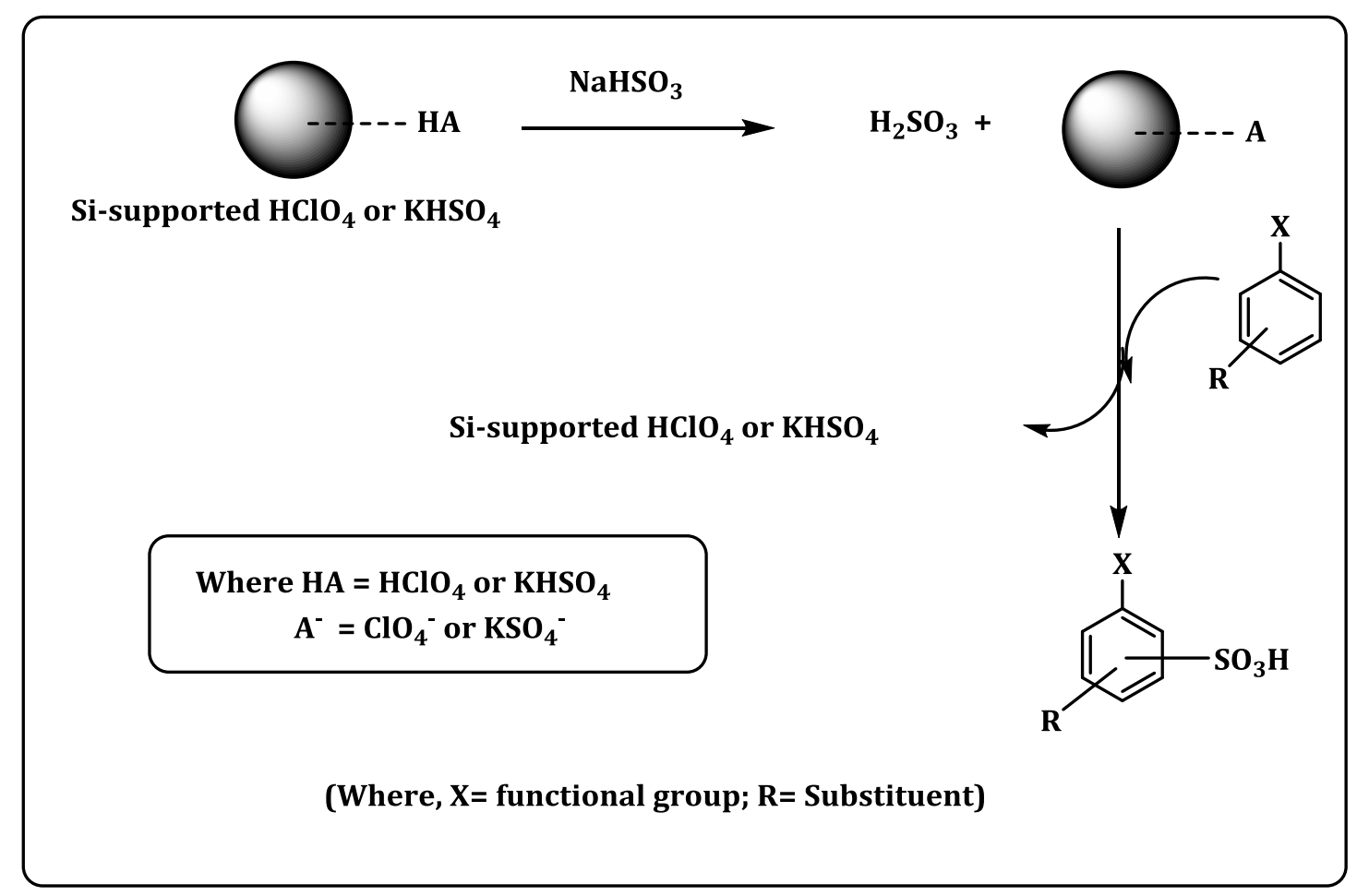

Scheme 2. Mechanism of sulfonation of aromatic

To examine the reusability of the catalysts $\left(\mathrm{SiO}_{2} / \mathrm{HClO}_{4}\right.$ and $\left.\mathrm{SiO}_{2} / \mathrm{KHSO}_{4}\right)$ after completion of the reaction, the catalysts were separated from the reaction mixture by simple filtration, treated with ethyl acetate, and dried. The catalyst thus obtained was reused under otherwise similar conditions (same set of experimental conditions were used in initially) and used again to corroborate the results obtained earlier. The recycled catalysts were found to be active up to four or five cycles, with a slight reduction of catalytic activity.

\section{Conclusion}

In summary, in the present work, we have developed 2, 4, 6-trichloro-1, 3, and 5-triazine / $\mathrm{KHSO}_{4}$ (TCTA- $\mathrm{KHSO}_{4}$ ) reagent for selective sulfonation of aromatic hydrocarbons under conventional reflux conditions with continuous stirring. Typical supports include various kinds of carbon, alumina, and silica. The support is generally inert and does not participate in the catalytic reactions. Solid-supported reagents/catalysts are easily removed from reactions by filtration. After due purification, it can be recycled for another batch reactions. Thus, the supported catalysts are not only economical and efficient, but also enivironmentally-sound. Reagents on solid-support react differently, mostly more selectively, than their unbound counterparts. The reactions afforded very good yields of sulfonated products with good selectivity. 


\section{Acknowledgments}

The authors thank Prof. P.K. Saiprakash, and Prof. T. Navaneeth Rao (former Vice-chancellor, O.U) for their constant encouragement.

\section{References}

[1]. Gilbert E.E., Sulfonation and Related Reactions, Wiley, NY, 1965

[2]. Cerfontain H.J.A., Schaasberg Z.R.H., Coombes R.G., Hadjigeorgion P., Tucker G.P. J. Chem. Soc. Perkin Trans., 1985, 2:659

[3]. Gilbert E.E. Chem. Rev., 1962, 62:549

[4]. Cerfontain H. Mechanistic Aspects in Aromatic Sulfonation and Desulfonation, Interscience Publishers, New York, 1965

[5]. Sülzle D., Verhoeven M., Terlouw J.K., Schwarz H. Angew. Chem. Int. Ed. Engl., 1988, 27:1533

[6]. Umemoto T., Tomozwaza G.J. Org. Chem., 1995, 60:6563

[7]. Cerfontain H., Lambrechts H.J.A., Schaasberg Z.R.H., Coombes R.G., Hadjigeorgion P., Tucker G.P.J., Chem. Soc. Perkin Trans., 1985, 2:659

[8]. Wuts P.G.M., Wilson K.E. Synthesis, 1998, 1593

[9]. Corby B.W., Gary A.D., Meaney P.J., Falvey M., Lawrence G.P., Smyth T.P.J. Chem. Res. Synop., $2002,7: 326$

[10]. Bochkareva T.P., Yakovlev I.P., Passet B.V., Sheiko M.A.J. Org. Chem., 1989, 25:1346

[11]. Mirjalili B.F., Zolfigol M.A., Bamoniri A.H., Zarei A. Phosphorus, Sulfur Silicon Relat. Elem., 2003, 178:1845

[12]. Smith M.B., March J. Advanced Organic Chemistry: Reactions, Mechanisms, and Structure (6th ed.), New York: Wiley-Interscience, 2007

[13]. Suter C.M., Weston A.W. Org. React., Doi: 10.1002/0471264180.or003.04

[14]. Breton G.W.J. Org. Chem., 1997, 62:8952

[15]. Ramesh C., Ravindranath N., Das B.J. Org. Chem., 2003, 68:7101

[16]. Sharma U., Katoch D., Sood S., Kumar N., Singh B., Thakur A., Gulati A. Indian J. Chem., 2013, 52B: 1431

[17]. Sheldon R.A., Arends I.W.C.E., Hanefeld U. Green Chemistry and Catalysis, Doi: 10.1002/9783527611003.ch2

[18]. Kaur M., Sharma S., Bedi P.M.S. Chin. J. Cat., 2015, 36:520

[19]. Baghernejad B. European J. Chem., 2012, 3:125

[20]. Wang B., Gu Y., Luo C., Yang T., Yang L., Suo J. Tetrahedron Lett., 2004, 45:3369 
[21]. Wilson K., Clark J.H., Pure Appl. Chem., 2000, 72:1313

[22]. Siddiqui Z.N., Farooq F. J. Mol. Cat. A: Chemical., 2012, 363-364:451

[23]. Siddiqui Z.N. Arabian J. Chem., Doi: org/10.1016/j.arabjc.2015.06.013

[24]. Hemanth Sriram Y., Fatima T., Satish Kumar M., Rajanna K.C., Venkateswarlu M., Sai Sudhakar M., Raju R.M., Iran. Chem. Commun., 2017, 5:352

[25]. Anastas P., Warner J. In Green Chemistry: Theory and Practice; Oxford University Press: New York, 1998

[26]. Anastas P.T., Kirchhoff M.M. Acc. Chem. Res., 2002, 35:686

[27]. Lidström P., Tierney J., Wathey B., Westman J. Tetrahedron., 2001, 5:9225

[28]. Varma R.S. Green Chem., 1999, 1:43.

[29]. Vivek P., Varma R.S. Chem. Res., 2008, 41:629

[30]. Oliver Kappe C. Angew. Chem. Int. Ed., 2004, 43:6250

[31]. Oliver Kappe C., Pieber B., Dallinger D. Angew. Chem. Int. Ed., 2013, 52:1088

How to cite this manuscript: Touheeth Fatima, Yeike Hemanth Sriram, Mukka Satish Kumar, Marri Venkateswarlu, Kamatala Chinna Rajanna*. Silica supported $\mathrm{HClO}_{4}$ and $\mathrm{KHSO}_{4}$ as reusable green catalysts for sulfonation of aromatic compounds under solvent-free conditions. Asian Journal of Green Chemistry, 2017, 1, 69-77. DOI: 10.22631/ajgc.2017.95574.1016 